\title{
¿Cómo hacer la Alianza del Pacífico amigable para la región?*
}

¿How to make Pacific Alliance friendly for the region?

Laszlo Vladimir Palotas Kelen', Claudia Marcela Duarte Pulido

\section{Resumen}

Este ensayo caracteriza brevemente la Alianza del Pacífico (ALP) y la ubica entre las tradiciones alternativas del regionalismo y del panamericanismo. Analiza las membresías de la ALP (liberal, emergente pura) y del Mercosur (cohabitación). Compara los mandatos específicos de los dos esquemas con respecto a la función social, el recurso al arbitraje en el Centro Internacional de Arreglo de Diferencias Relativas a Inversiones y la unión aduanera. Subraya que la ALP debería consolidar rápidamente su cohesión, pues México y Chile están más vinculados a Brasil en el Mercosur.

\section{Palabras clave}

Alianza del Pacífico, Mercosur, complejidad institucional, balanceo institucional.

\section{Códigos de clasificación JEL: F15, N76}

\begin{abstract}
This paper briefly characterizes the Pacific Alliance (ALP) and ranks it among the alternative traditions of the regionalism and Pan Americanism. It analyzes the ALP memberships (pure liberalemergent) and Mercosur (cohabitation). It compares the specific mandates of the two schemes regarding the social function, the use of arbitration at the International Centre for Dispute Settlement related to Investment and the customs union. It stresses that the ALP should rapidly consolidate their cohesion as Mexico and Chile are more closely linked to Brazil-Mercosur.
\end{abstract}

\section{Keywords}

Pacific Alliance, MERCOSUR, institutional complexity, institutional balancing.

Resultado de la investigación "Balanceo institucional de Colombia con la Alianza del Pacífico y la UNASUR”, del grupo de investigación Integración y Globalización de los Negocios de la Facultad de Negocios Internacionales, Universidad Santo Tomás Seccional Bucaramanga, Colombia. Los autores agradecen los comentarios de Fabio Barba García y Nohora Rodríguez Chacón.

1 Doctor en Relaciones Internacionales. Docente-investigador de la Universidad Santo Tomás Seccional Bucaramanga, Colombia. Correo electrónico: donlaszlo@yahoo.com

2 Magíster en Análisis de Problemas Políticos, Económicos e Internacionales Contemporáneos. Docenteinvestigadora de la Universidad Santo Tomás Seccional Bucaramanga, Colombia. Correo electrónico: claudiamarceladuarte@gmail.com 


\section{Introducción}

Hace poco aún, la Alianza del Pacífico (ALP) y el Mercado Común del Sur (Mercosur) fueron identificados con distintos, incluso antagónicos, modelos de integración-cooperación regional: un "Modelo Pacífico", caracterizado como liberal, dinámico, innovador, y un "Modelo Atlántico"', marcado de proteccionista, politizado, estancado (Tvevad, 2014).

Según Kotschwar (2014), los dos esquemas representan "polos en una Latinoamérica bifurcada" en términos de política económica, y los socios (ALP) superan los miembros- Mercosur respecto a una serie de indicadores de competitividad $^{5}$.

La ALP -lanzada en 2011 con intensa promoción presidencial mediática de su "modelo"- precipitó un reordenamiento en la arquitectura institucional de Suramérica.

El Mercosur completó la admisión de Venezuela, abriendo paso al acceso de Bolivia y al posible ingreso de Ecuador. La ALP atrajo como observadores a Uruguay y Paraguay, socios-menores del Mercosur. Esto reavivó la discusión, en Brasil particularmente, sobre una reversión del bloque de una unión aduanera (UA) incompleta a una zona de libre comercio (ZLC), o una "flexibilidad" equivalente.

Sin embargo, el gobierno centro-izquierda de Bachelet -que en 2014 relevó al gabinete centro-derecha de Piñera en Chile- logró reunir los integrantes de la ALP y del Mercosur, para explorar vías de su "convergencia en la diversidad" (Muñoz, 2014; Cepal, 2014). El presidente colombiano Juan Manuel Santos, incluso negó que existiera competencia entre los dos esquemas (Bloomberg, 2014).

De ahí las preguntas: ¿Qué clase de competencia existe entre la ALP y el Mercosur? ¿En qué medida la ALP se presta para balancear al Mercosur? ¿Qué implicaría una reversión del Mercosur a una ZLC? ¿Sería un cambio desfavorable en la arquitectura regional para Brasil? ¿Cómo hacer la ALP amigable para la región? ¿Sería deseable una convergencia ALP-Mercosur?

3 Se compromete firmemente con la integración vector-mercado, responde a la globalización, abriendo mercados, ofreciendo oportunidades y seguridad jurídica a los inversionistas (Tvevad, 2014).

4 Introvertido, incumple sus objetivos de integración comercial, se convierte en una ineficiente asociación política; sin acuerdos con los mercados líderes, sus relaciones externas se estancan, incluso su comercio intrabloque se ve afectado por medidas proteccionistas (Tvevad, 2014).

5 Instituciones, infraestructura, entorno macroeconómico, uso eficiente de talento, eficiencia de mercados de bienes. 


\section{Marco conceptual, estructura}

Este ensayo utiliza conceptos como la complejidad institucional (Weiffen, Wehner, Nolte, 2013) y el balanceo institucional (He, 2007; Lee, 2012).

\section{Balanceo institucional}

Según el realismo institucional de He (2007), un mundo (región) multipolar y económicamente muy interdependiente hace más probable que los Estados elijan el balanceo institucional -es decir, el comportamiento balanceador mediante instituciones internacionales- en vez de establecer una alianza militar o acrecentar sus propios recursos bélicos.

En Suramérica, el poder está ampliamente distribuido: el predominio de Brasil es impugnado en repetidas ocasiones por potencias secundarias (Argentina, Venezuela, Colombia, Chile) (Flemes, Wehner, 2012) ${ }^{6}$. Es muy fuerte la proyección de poder (militar) estadounidense, y se perciben otras influencias externas (china, mexicana, europea, rusa).

En cambio, la interdependencia económica es aún modesta ${ }^{7}$ (debido al modelo primario exportador predominante históricamente) (Dabène, 2014). Esto hará el recurso al balanceo institucional menos probable (frente a comportamientos más duros) que en otras regiones. Por otra parte, explicará la proliferación de esquemas sin convincentes proyectos económicos, moldeables por intereses políticos y aprovechables para posicionamiento diplomático.

\section{Balanceo interinstitucional e intrainstitucional}

Lee (2012) flexibiliza al realismo institucional: no descarta cambios en el comportamiento balanceador sin invocar cambios en la distribución de poder y el grado de interdependencia económica ${ }^{8}$. Así relaja las dos variables independientes de He (2007), y debe buscar otros mecanismos causales para explicar el balanceo institucional. Con tal propósito, se centra en las estrategias de los Estados individuales, y distingue entre balanceo interinstitucional (realista puro) y balanceo intra-institucional (más liberal).

6 Estas potencias intermedias no buscan desestabilizar el orden regional, sino reducir las asimetrías existentes y aumentarle a Brasil los costos de políticas unilaterales (Flemes, Wehner, 2013).

7 Solo el 18\% de las exportaciones de Latinoamérica se ha dirigido a la propia región entre 2008-2013 y tal cuota en Suramérica es aún menor. En otras macro-regiones la cuota de las exportaciones intrarregionales ha sido mucho más alta: UE 63,4\%, TLCAN 48,5\%, ASEAN+5 49,1\% (Cepal, 2014, p. 22).

8 Lee cataloga el balanceo institucional como una forma de balanceo blando (de poder), mientras He lo cataloga aparte. 


\section{Balanceo interinstitucional}

Se refiere al comportamiento de un Estado que conforma una institución para balancear a un Estado-objetivo. Los Estados balanceadores compiten para atraer a otros Estados a su institución, mientras evitan incorporarse (más) a las instituciones dominadas por el Estado-objetivo. Un Estado recurre al balanceo interinstitucional con el fin de rediseñar la arquitectura institucional regional a expensas del Estadoobjetivo (Lee, 2012).

Hace dos años, el desempeño de la ALP como "contrapeso a otro tipo de integración" fue celebrado por un diplomático colombiano. Evidentemente, Ramírez (2012) se refirió al Mercosur, liderado por Brasil (y, en menor medida a la Alianza Bolivariana para los Pueblos de Nuestra América (ALBA), liderada por Venezuela).

Probablemente, tal balance o a través de la ALP era una respuesta a la insistencia de Brasil en incorporar a Venezuela al Mercosur (pese a su economía mucho más dirigida que las demás del bloque). Tal insistencia tenía fuerte motivo geoeconómico 9 .

\section{Balanceo intra-institucional}

Es la estrategia de los Estados en competencia que cooperan para crear una institución, cuando la demanda de bienes públicos es alta. Una vez creada la institución para proveer el bien público, los Estados en su seno demuestran comportamientos tanto cooperativos, como balanceadores (negociación, lucha, confrontación) (Lee, 2012).

Todos los Estados suramericanos concurrieron para crear la Unasur ${ }^{10}$, en la cual Brasil ofreció estabilidad regional como bien público ${ }^{11}$.

Un balanceo dentro de la Unasur, a través de la ALP, habría sido una coordinación política entre sus miembros suramericanos y México como potencia externa, fugazmente contemplada por Colombia y Chile (Piñera) (Nolte, Wehner, 2013).

\section{Complejidad institucional}

Weiffen, Wehner, Nolte (2013) analizan la complejidad institucional, identificando superposiciones entre membresías y mandatos de las organizaciones regionales,

9 Eje Caracas-Sao Paulo-Buenos Aires visto como posible columna vertebral de un mercado común, dada la complementariedad entre la economía petrolera de Venezuela, la industria pesada de Brasil y la agroalimentaria de Argentina (Falomir, 2014).

10 Unión de Naciones Suramericanas (2008): diseño geopolítico de Brasil para redefinir el regionalismo en el marco suramericano, excluyendo a México, su rival potencial en Latinoamérica (Sanahuja, 2012). A través de una serie de mediaciones ad hoc, ha desplazado la OEA de la resolución de conflictos en Suramérica. No es (aún) marco para integración comercial.

11 Gradualmente, Brasil extendió paraguas de estabilidad a Argentina, al Mercosur, a la Organización del Tratado de Cooperación Amazónica, a la Unasur. Elevó su presupuesto de defensa a un nivel superior al total de gastos militares de las potencias secundarias (Dabène, 2014). 
e indagando sus causas. Nolte (2014) destaca la centralidad de la Unasur ${ }^{12}$ en la arquitectura institucional suramericana y la importancia de estudiar los diferentes esquemas en su interacción.

- Los miembros suramericanos de la ALP son también miembros asociados del Mercosur, mientras México tiene acuerdos de complementación económica (ACE) ${ }^{13}$ parciales con el bloque (y sus integrantes). Los mandatos generales de los dos esquemas se superponen en la medida en que se refieren a la integración económicacomercial $^{14}$.

Para tener cohesión, la ALP debe estrechar los lazos de comercio-inversión entre sus miembros más aceleradamente que sus lazos con el Mercosur. En esta etapa, los socios de la ALP han privilegiado la construcción de su nuevo esquema. Sus conversaciones con el Mercosur se han limitado a temas no arancelarios.

Ambos esquemas atraen -conforme a las diferencias entre sus mandatos específicos- miembros diferentes. La ALP -liberal-emergente- solo compite por miembros afines. En el Mercosur, solo Uruguay y Paraguay siguen adeptos al liberalismo económico. Uruguay (más desarrollado) podría ser admitido también a la ALP, si recibiera "flexibilidad" de sus socios del Mercosur. Ser del Atlántico no es obstáculo para el acceso a la ALP.

\section{Estructura}

Este ensayo caracteriza la ALP y la ubica entre regionalismo/panamericanismo. Analiza las membresías de la ALP (liberal-emergente pura) y del Mercosur (cohabitación). Compara los mandatos específicos de ambos respecto a la función social, al Centro Internacional de Arreglo de Diferencias Relativas a Inversiones $(\mathrm{CIADI})^{15}$, Constata que la ALP debería consolidar rápidamente su cohesión (pues México y Chile están más vinculados a Brasil-Mercosur). Examina la relación de cada miembro-ALP con Brasil (Estado-objetivo de ambos balanceos). Evalúa la competencia de la ALP y Mercosur como de baja intensidad. Finalmente hace conjeturas: Si la ALP no se consolidara un macro de ACE en la Unasur (sin México) sería posible. Si se consolidara un acuerdo ALP y Mercosur con México permitiría a Brasil evitar la reversión de su bloque a una zona de libre comercio.

12 Membresía abarcadora, múltiples mandatos (seguridad/defensa, infraestructura/energía/ambiente, educación/ salud).

13 Acuerdos preferenciales entre miembros de ALADI. Algunos desgravan casi todo el intercambio de bienes, otros solo una parte o en un sector específico.

14 Partimos de las preguntas finales de Nolte (2014). Si bien los mandatos-Mercosur van más allá de la integración económico-comercial, sus dimensiones social/productiva son conexas.

15 CIADI (célebre por laudos favorables a inversionistas privados) 


\section{¿Cómo encaja la ALP entre panamericanismo/regionalismo?}

Se caracteriza escuetamente la ALP para ubicarla en la tradición alternativa de panamericanismo/regionalismo ${ }^{16}$.

\section{ALP - rasgos básicos}

Esquema de regionalismo reabierto, asentado sobre $\mathrm{TLC}^{17}$ entre México (norteamericano), Chile, Colombia y Perú (suramericanos), ligados por TLC a EE. UU. ${ }^{18} \mathrm{y}$ otros mercados relevantes.

Aspira a "integración profunda" mediante:

a). Compromisos de libre movilidad de bienes y servicios con protección de inversiones directas: características de una ZLC.

b). Acciones a favor de la libre circulación de personas (empresarios, estudiantes, turistas) y de capitales (mercado bursátil integrado): signos distintivos de un mercado común (None, 2014) ${ }^{19}$.

Protocolo Adicional (2014) - al Acuerdo Marco (2012) - crea una ZLC (bienes):

Elimina los aranceles sobre el $92 \%$ de los bienes a su entrada en vigor ${ }^{20}$; desgravará el resto gradualmente: $7 \%$ en 3-7 años, 1\% -bienes sensibles (agrícolas)- en 15-17 años ${ }^{21}$.

Complementa, actualiza, profundiza las normas contenidas en los acuerdos vigentes entre los miembros (TLC bilaterales, CAN entre Colombia-Perú) que ya han desgravado casi el $88 \%$ del universo arancelario.

Armoniza las reglas de origen (de los acuerdos bilaterales) y establece un mecanismo de acumulación, estimulando las empresas a conformar cadenas regionales de valor ${ }^{22}$.

16 Panamericanismo: esquemas hemisféricos con participación directa de EE. UU. (para afianzar-reforzar su hegemonía, extender sus regímenes jurídicos, excluir las potencias extra-continentales, implementar blandamente la Doctrina Monroe). Tres ciclos: breves períodos de construcción institucional interamericana, seguidos por prolongadas parálisis, causadas por recaídas de EE. UU. al unilateralismo (Mace, Thèrien, 2007). Regionalismo: alternativa latinoamericana al panamericanismo. Visión bolivariana: excluye a EE. UU., reserva opción de alianza extra-continental. Doctrina Calvo: protegió la soberanía económica de los Estados latinoamericanos (Mace, Bélanger, 1999). Tres olas desde 1960: no ha consolidado un proyecto único de integración económica, aunque ha llegado a establecer una organización continental de concertación política (CELAC). Los esquemas subregionales han constituido bases independientes de poder, tanto frente a las instituciones interamericanas como a los otros esquemas subregionales.

17 Tratados de libre comercio.

18 Estados Unidos.

19 Personas: los miembros-ALP mutuamente eliminaron las visas para turistas y viajeros de tránsito o negocio por seis meses. Se introducirá visa común para turistas procedentes de terceros países. Programa Vacaciones y Trabajo: permite a jóvenes de los países-ALP trabajar-estudiar en otro país-ALP durante un año. Capitales: adhesión de México, iniciada en 2014, hará el MILA comparable a la Bovespa brasileña.

20 A mediados de 2015.

21 Según lista separada para cada miembro.

22 La armonización permitirá a los productores de un país-socio exportar a los demás bajo los mismos requisitos para arancel-cero. La acumulación de origen facilitará el uso de partes-componentes-insumos de los cuatro países en la producción de bienes en la ZLC. 
Los autopartistas mexicanos, por ejemplo, no solo podrán exportar sus piezas a Colombia con arancel cero, sino las piezas mexicanas, incluidas en carros ensamblados en Colombia, se considerarán como colombianas, cuando estos carros se exporten a otro país socio ${ }^{23}$.

Para estimular inversiones recíprocas, codificar reglas de apertura y protección, incluyendo el arbitraje internacional vinculante en controversias inversionistaEstado, con opción de recurrir al CIADI. Para atraer inversiones en ensamblaje, requiere valor de contenido regional (VCR) para carros de turismo $(35 \%)^{24}$, más alto para autopartes (45\%). En general, su protección frente a terceros es moderada ${ }^{25}$.

Busca proyección colectiva hacia Asia-Pacífico: insertar sus (futuras) cadenas regionales de producción en las norteamericanas y asiáticas ${ }^{26}$.

Contiene disposiciones relativas a servicios profesionales, telecomunicaciones, servicios financieros, transporte marítimo/aéreo, que van más allá de los acuerdos bilaterales existentes (Echebarría, Estevadeordal, 2014) ${ }^{27}$.

Tiene dos grandes hándicaps:

1. Escaso comercio intrarregional con baja intensidad intra-industrial ${ }^{28}$ : absorbe apenas un 4\% de las exportaciones de sus miembros (el Mercosur un 14\%). México y Chile están más ligados comercialmente al Mercosur/Brasil que a la propia ALP.

Entre las diez principales relaciones comerciales que involucran miembros de los dos esquemas, hay una sola (México-Colombia) que vincula dos socios-ALP (sexto lugar, 4,4\% del intercambio total $)^{29}$.

Entre los socios-ALP, solo el comercio Colombia-Perú es principalmente intraindustrial $^{30}$ (si bien existe potencial en el intercambio México-Colombia, México-

23 La fortaleza manufacturera de México complementaría las economías-socias, basadas más en productos primarios. Chile-Colombia, que a Asia venden mayoritariamente recursos naturales, a Latinoamérica exportan manufacturas en mayor proporción. Si la ALP desarrolla su comercio intrazona, atrayendo una variada gama de empresas, incluyendo pymes, su dependencia de las exportaciones primarias disminuirá, mejorando la composición de su comercio con Asia (Mander, 2014).

24 Mucho menos que el TLCAN y menos que el Mercosur.

25 En ningún caso el VCR es superior al 50\% (Anexo 4.2 - Protocolo Adicional).

26 Como las norteamericanas, las cadenas asiáticas se caracterizan por procesos productivos muy fragmentados y alto porcentaje de bienes intermedios en el comercio intrarregional. Se remontan a los 80, cuando Japón subcontrató la fabricación de insumos y manufacturas livianas a empresas en otros países de Asia Oriental. La relación se intensificó con la inclusión de pymes, aprovechando los menores costos laborales en estos países (Foxley, 2014). Desde 2005, China ha relevado a Japón como centro de esta "Fábrica Asia", sirviendo como plataforma de exportación para sus vecinos, proveedores de bienes intermedios, a partir de los cuales produce los bienes finales que exporta a EE. UU./UE (Cepal, 2012).

27 En facilitación de comercio, promueve: cooperación entre servicios de aduana, simplificación administrativa, interoperabilidad entre las "ventanillas únicas" de exportaciones de los miembros, certificación electrónica.

28 Comercio de dos vías: cuando dos países se exportan recíprocamente productos pertenecientes a una misma industria (economías de escala, encadenamientos productivos).

29 Argentina-Brasil (28,4\%), México-Brasil (7,6\%), Chile-Brasil (7,1\%). Cinco pares más (ocho de los diez) incluyen a Brasil. Cuatro son entre miembros-Mercosur, cinco entre un miembro-Mercosur y uno-ALP (Cepal 2014, 43). La ALP solo responde por el 2,3\% de las ventas de México y el 0,8\% de sus compras (Blanco 2014).

30 Índice Grubel \& Lloyd superior a 0,33. 
Chile, Chile-Perú ${ }^{31}$, y la dinámica es creciente). La primera relación bilateral intra-ALADI ${ }^{32}$-tanto comercial, como productiva- es (lejos) Brasil-Argentina y la segunda es México-Brasil (Cepal, 2014, Aladi, 2012).

2. Discontinuidad geográfica ${ }^{33}$, graves problemas de infraestructura.

\section{La ALP entre regionalismo/panamericanismo}

ALP: pertenece al regionalismo (esquema latinoamericano sin participación de EE. UU.), pero sus características de fondo la vinculan al panamericanismo:

Consta de aliados cercanos de EE. $\mathrm{UU}^{34}$. Se deriva de la secuencia Iniciativa Empresa de las Américas - IEA ${ }^{35}-\mathrm{TLCAN}^{36}-\mathrm{ALCA}^{37}$-TLC-bilaterales (Briceño, 2013). Formaliza la "coalición de los dispuestos" a trabajar con EE. UU., continuando el paradigma centrado en liberalización comercial, encarnado en la abandonada ALCA (Hershberg, 2014).

Absorbe la estrategia de integrar a Gran-Norteamérica vía entrelazamiento (económico-energético-infraestructural) entre México y los centroamericanos, a base de sus respectivos TLC con EE. UU./UE ${ }^{38}$ (Sanahuja, 2012). Incluye el Plan Puebla-Panamá (2001) rebautizado Proyecto Mesoamérica (2008). Colombia se unió al proyecto en $2006^{39}$.

Busca la proyección colectiva a Asia-Pacífico en línea con la $\mathrm{ATP}^{40}$, cuyos participantes tienen TLC con EE. UU. Tal "aspecto triangular" se reforzó con la adhesión de EE. UU. a la ALP como observador en 2013 (Tvevad, 2014).

Es percibida por la izquierda latinoamericana como instrumento de EE. UU. para socavar los patrones de integración regional, alternativos a los TLC (Nolte, Wehner, 2013). En Brasil y China es vista como "mascarón de proa" de la ATP. Sectores

31 IGL entre $0,10-0,33$.

32 Asociación Latinoamericana de Integración (1980), sucesora de la ALALC (México y diez suramericanos, plus Cuba, Panamá): basada en Cláusula de habilitación, registra cualquier ACE entre sus miembros, estimula su convergencia, sin fijar plazo para alcanzar ZLC.

33 En Centroamérica: varios no-miembros. En Suramérica, Ecuador no es miembro: discontinuidad a lo largo de la Costa Pacífica.

34 No incluye el ideal de autonomía (del regionalismo) frente a EE. UU. (Betancourt, 2012).

35 Iniciativa Empresa de las Américas: Bush (padre) visualiza red hemisférica de TLC bilaterales, pero, a excepción de México, solo ofrece limitados acuerdos de comercio-inversión a los latinoamericanos.

36 Tratado de Libre Comercio de América del Norte: extendió a México regímenes GATT-plus (servicios, inversiones, compras públicas, propiedad intelectual) muchos ya incluidos TLC EE. UU. y Canadá. Además de la desgravación entre sus miembros, elevó la protección a nivel regional con estrictas reglas de origen (sector automotriz/textil-ropa). Así profundizó una integración en cadenas de valor, donde las empresas mexicanas y estadounidenses intercambian piezas-partes-insumos. Las plantas que elaboran los productos finales se instalan en uno u otro país, según sus ventajas comparativas (Foxley, 2014).

37 Área de Libre Comercio de las Américas: proyecto estadounidense para la extensión (hegemónica) de los regímenes del TLCAN al resto del hemisferio, abandonado tras diez años de negociación.

38 Unión Europea.

39 Se trata de interconectar las redes eléctricas de Colombia y Panamá y, cuando el sistema de interconexión de los centroamericanos esté plenamente operativo, todas las redes de Gran-Norteamérica (O'Keefe, 2014).

40 Asociación Transpacífica: macro-TLC en Asia-Pacífico, negociado bajo liderazgo estadounidense. 
importantes en Brasil interpretan la ATP como el "ALCA 2.0". China la ve como un proyecto de EE. UU. (que domina la definición de sus estándares) para mejorar su posición en las cadenas asiáticas de valor (hoy articuladas en torno a China) (Rosales, $2013)^{41}$.

\section{Dos matices}

1. En realidad, la ALP difiere del TLCAN-ATP en su objetivo de avanzar hacia la libre circulación de personas (Acuerdo Marco, 2012). Por otra parte, el Protocolo Adicional (2014), más allá de la desgravación arancelaria y las reglas de origen, a menudo se limita a orientaciones ${ }^{42}$, sin fijar todavía normas-disciplinas precisas. Esto dista de los minuciosos regímenes-TLCAN, ratificados como paquete único, y recuerda los protocolos-Mercosur.

2. La administración Obama insertó las relaciones interamericanas en el contexto transpacífico ${ }^{43}$, e influyentes congresistas apoyaron la adhesión colombiana a la ATP como un paso hacia el TLC hemisférico (Rubio, 2014). Sin embargo, la normalización con Cuba -y su entrada en el Proceso de Cumbres sin democratización previa, con el abandono oficial de la Doctrina Monroe- podría resucitar un panamericanismo ya pos-hegemónico.

\section{ALP-Mercosur: membresías}

La ALP seleccionó una membresía neoliberal y solo atrae-admite miembros afines. En el Mercosur, solo los dos pequeños son (económicamente) liberales. La homogeneidad de la ALP promete mejor cumplimiento de compromisos que la cohabitación variable del Mercosur.

\section{ALP - pureza liberal-emergente}

Seleccionó su membresía a través de dos divisiones: la de la $\mathrm{CAN}^{44}$ y la del ARCO del Pacífico Latinoamericano.

41 China multiplica vertiginosamente su comercio con Latinoamérica en los 2000; aumenta inversiones directas desde 2010. Esto dinamizó crecimiento de varias economías, ayudó a resistir efectos recesivos de crisis financieras occidentales; desaceleración en años recientes. Riesgos: Más relaciones centro-periferia, reprimarización. Excesivo endeudamiento (Quenan, 2014). Falta ver, si la cooperación Celac remedia tales inconvenientes.

42 Así, en materia de normas técnicas y fitosanitarias, prevé transparencia y cooperación regulatoria, acuerdos de mutuo reconocimiento, institucionalidad para la aplicación de tales medidas con base científica (Echebarría, Estevadeordal, 2014).

43 Estrechando lazos con los pocos latinoamericanos dispuestos a secundar su "pivote a Asia" (Brenner, Hershberg, 2014).

44 Comunidad Andina de Naciones (reemplaza al GRAN): se "presidencializa", pierde rasgos supranacionales, abandona la industrialización por sustitución de importaciones. 


\section{División de la CAN}

La ALP puede ser vista como la última mutación del PA/GRAN ${ }^{45}$ : recupera (al neoliberal acomodado) Chile, reemplaza (los rezagados populistas-izquierdistas) Bolivia y Ecuador por (el neoliberal emergente) México, y deja fuera (la antisistémica) Venezuela (Palau, 2014): un giro de 180 grados (del regionalismo cerrado del GRAN al regionalismo reabierto de la ALP) en cuatro décadas.

Si el G3 ${ }^{46}$ ya había diluido la CAN, los TLC de Colombia y Perú con EE. UU. (que rompieron la disciplina colectiva-UA $)^{47}$ la desarticularon aún más ${ }^{48}$. Como protesta, Venezuela se retiró de la CAN-G3 (2006), buscando en el Mercosur compensar los beneficios perdidos.

- La CAN remanente se dividió entre dos populistas de izquierda, partidarios de su convergencia con el Mercosur (Bolivia-Ecuador) y dos liberales persistentes (Colombia-Perú) que iniciaron un proyecto alternativo (Dabène, 2014).

\section{División del ARCO}

En 2006, el presidente peruano Alan García (viendo a Venezuela abandonar la CAN y a Bolivia dirigirse al ALBA $)^{49}$ planteó una alianza de países latinoamericanos (ribereños del Pacífico) que firmaron TLC con EE. UU.

Así, se estableció el ARCO en 2007 tras una ministerial celebrada en Cali, comprendiendo (junto a Colombia, Chile, México y Perú) a Panamá, Costa Rica, El Salvador, Guatemala, Honduras, Nicaragua y Ecuador ${ }^{50}$.

Luego, García propuso que Panamá, Colombia, Ecuador, Perú y Chile conformaran un “área de integración profunda” (Motivación, 2012). Según las Memorias (2012) de la Secretaría de Economía de México: "Chile y Colombia promovieron que en esta iniciativa participara también México, propuesta que fue aceptada por Perú. Ecuador no respondió la invitación y si bien Panamá sí lo hizo, se acordó que su participación fuera en calidad de observador".

45 Pacto/Grupo Andino: desconectarse temporalmente de economía mundial para construir base industrial. Fuerte influencia europea (vocación-UA, complejo diseño institucional, rasgos supranacionales).

46 Grupo de los Tres (Colombia y Venezuela con México): adopta regímenes modelo-TLCAN en aquellas áreas (inversión, servicios, compras públicas, derechos de propiedad intelectual) que el GRAN no había regulado (o menos sofisticadamente que el TLCAN).

47 En 2004, los miembros-CAN flexibilizaron sus objetivos regionales, permitiendo negociar TLC con terceros.

48 La CAN tuvo que abandonar su meta-UA (AEC iba a quedar aún más perforado). Su normativa común de propiedad industrial fue transgredida por el régimen de protección de propiedad intelectual adoptado por Colombia-Perú en TLC. Sistema de Franjas de Precios (productos agropecuarios) eliminado entre dos andinos EE. UU.

49 Alianza Bolivariana para los Pueblos de Nuestra América: antiliberal, cooperación subregional Estado-centrista, objetivos sociales por encima de todo. Depende de un solo país (en crisis progresiva) y un solo producto (de precio volátil).

50 Ecuador sin TLC con EE. UU., pues Correa suspendió negociaciones. Nicaragua y Ecuador no comulgaban con el modelo neoliberal, posteriormente, se adhirieron al ALBA. 
Así, la ALP se lanzó, como un esquema homogéneo de cuatro emergentes neoliberales, incorporando a México. Si bien la Declaración (2011) de la Cumbre de Lima creó el nuevo esquema “en el marco del ARCO”, los cofundadores efectivamente se libraron de sus socios rezagados (por lo menos temporalmente).

Esencialmente, el Gobierno colombiano justificó la decisión con un argumento de velocidades diferenciadas ${ }^{51}$. Sin embargo, mientras la CAN subsistió (si bien bajo delicada "reingeniería"), el ARCO no ha vuelto a dar señales de vida.

\section{Mercosur - diferentes ideologías y tamaños}

Dos rasgos caracterizan su membresía: cohabitación del moderado Brasil con socios ideológicamente diversos. Enormes asimetrías intra-bloque resentidas por los pequeños.

\section{Cohabitación}

En los noventa, Argentina había practicado un neoliberalismo radical (con amplia privatización), al lado de un Brasil gradualista en la liberalización ${ }^{52}$. Tras la ruptura de la Convertibilidad ${ }^{53}$, Argentina cayó al otro extremo, adoptando un ardiente nacionalismo económico.

Brasil, bajo Lula, volvió a ser más introvertido, apoyando su crecimiento en la demanda interna (con mejor distribución).

El lanzamiento ALP empujó al Mercosur a completar la incorporación de Venezuela ${ }^{54}$ y proceder a la admisión de Bolivia ${ }^{55}$. Tal ampliación fragmenta, politiza al bloque aún más.

51 Según la Motivación (2012) del Proyecto de Ley colombiana para la aprobación del Acuerdo Marco de la ALP, "los avances del ARCO han sido limitados, particularmente en materia de convergencia e integración comercial, por diferencias respecto a los objetivos y mecanismos para lograrlo. Chile, Perú, Colombia y México conformarían, en la Alianza del Pacifico, el grupo más homogéneo y el que probablemente estaría en mejores condiciones para avanzar en esta iniciativa".

52 El Mercosur arrancó (1991) con rápida desgravación arancelaria (90\% de bienes para 1995). A iniciativa brasileña (para resistir sutilmente el ALCA) se monta AEC incompleto (1995): a su rededor, se concluyen ACE 4+1 con Chile, Bolivia (1996) y un ACE 4+4 con los demás del CAN (2003). Se va negociando un ALCSA.

53 Camisa de fuerza monetaria que fijó el tipo de cambio en $\$ 1=1$ peso. Caja de conversión: por cada dólar que sale del país, saca un peso de circulación (reduciendo también el componente peso de la base monetaria: automático efecto recesivo). Cuando se desplomó, el peso perdió el $70 \%$ de su valor, se congelaron los ahorros, se suspendieron pagos de deuda soberana (también a los bonistas extranjeros).

54 En 2012, Paraguay, cuyo senado había bloqueado el acceso definitivo de Venezuela, fue suspendido del Mercosur por sus tres socios, después de que el presidente Lugo fuera destituido con vicios en las reglas del procedimiento. Si bien la suspensión fue jurídicamente válida, la admisión de Venezuela no la era, pues (en virtud del Tratado Constitutivo del Mercosur) habría debido ser aprobada con la unanimidad de todos los miembros (y Paraguay no dejaba de ser miembro). Terminada la suspensión con la elección libre del presidente Cartes, el nuevo Senado paraguayo aprobó la admisión de Venezuela según (Falomir, 2014).

55 Bolivia estaba en lista de espera desde 2007. Su acceso se completará en 2015. Quiere conservar también su membresía en CAN. 


\section{Asimetrías}

El Mercosur se lanzó incluyendo a Uruguay y Paraguay en una integración económica iniciada entre Argentina y Brasil. Tal inclusión introdujo un segundo nivel de asimetría en el esquema, en la medida en que la brecha entre los dos pequeños y los dos grandes es mayor que la existente entre los dos grandes.

Las asimetrías suscitan reticencias en los pequeños hacia Brasil como líder y, en menor medida, hacia Argentina, dificultando objetivos como la coordinación de políticas comerciales o el mercado común (Falomir, 2014).

\section{Membresías y compromisos}

La ALP revela firme voluntad de cumplir sus compromisos. El Mercosur tiene fama de incumplimientos, de renegociaciones.

\section{$A L P$}

Sus bases estratégicas plasmadas en su red de TLC en armonización y sus requisitos de acceso deben asegurar su homogeneidad liberal a través de cambios de gobiernos.

Tales requisitos son: los observadores, para ser candidatos de acceso deben tener TLC vigentes con la mitad de los miembros. Los "observadores candidatos" (Costa Rica, Panamá) solo podrán acceder a miembros plenos, una vez tengan TLC con todos los miembros actuales. Los nuevos miembros deben aceptar las obligaciones preexistentes.

Compromiso reafirmado: Humala, Peña Nieto, a la izquierda de sus antecesores, reafirmaron sus posturas a favor de la ALP (Tvevad, 2014). Incluso Bachelet mantuvo el compromiso básico con el esquema, sin cuestionar el modelo librecambista de crecimiento y desarrollo en que se apoya. Su canciller Muñoz (2014 $)$ afirmó que Chile no quería diluir la integración ALP, tan solo limitarla a la dimensión económica y comercial.

Otras muestras de seriedad: Canadá desistió de su propósito inicial de ingresar, cuando se dio cuenta que la ALP no ablandaría su exigencia de suprimir visas (Kotschwar, 2014) ${ }^{56}$. Tanto el Acuerdo Marco (2012) como el Protocolo Adicional (2014) han sido debidamente sometidos a ratificación legislativa en cada socio. Sin embargo, la ALP apenas está debutando, sin afrontar aún retos de integración más madura ${ }^{57}$.

56 En 2009, Canadá restableció la obligación de visas para mexicanos.

57 Así, México - que ajusta su política cambiaria a la estadounidense-difícilmente podrá coordinarla con sus socios de ALP. 


\section{Mercosur}

Subsisten numerosas excepciones a la ZLC intra-bloque, el comercio automotriz continúa administrado ${ }^{58}$, abundan las barreras no arancelarias. La implementación del Código Aduanero aprobado en 2010 (que prevé eliminar la doble imposición de arancel $)^{59}$ se ha complicado.

Los dos protocolos de inversiones (provenientes del interior y exterior) aprobados en los noventa, nunca entraron en vigor. En 2010 se decidió elaborar un acuerdo (liberal) de inversiones intra-bloque, pero las discrepancias impidieron el avance.

Entre 1999 y 2002, el Mercosur atravesó una crisis existencial. Brasil y Argentina se embrollaron en un espiral destructivo de medidas y contramedidas ${ }^{60}$ que solo tocó fondo tras la ruptura de la Convertibilidad (Bechle, 2011).

Argentina, cuyo acceso a los mercados financieros está severamente limitado por sus impagos y renegociaciones de bonos de deuda soberana ${ }^{61}$, necesita producir balanzas positivas ${ }^{62}$, para lograrlo, congela precios (diferentes), grava exportaciones (lucrativas como la soya) y aplica medidas de defensa comercial frente a socios como a terceros.

Con el ingreso de Venezuela (en crisis económica, financiera, política) las excepciones se han convertido en la regla (Sorj, 2014).

Las decisiones críticas se toman por (directa) diplomacia presidencial, combinada con presidencialismo: el poder de los presidentes suramericanos para concluir acuerdos sin buscar aprobación legislativa (Malamud, 2013).

\section{Diferentes mandatos atraen diferentes miembros}

Se examinan diferencias entre ALP y Mercosur en cuanto a mandatos específicos, como recurso al CIADI, función social y UA. Los diferentes mandatos atraen otros miembros.

58 Además de Norteamérica, las multinacionales automotrices concentran sus inversiones hemisféricas en el Mercosur, buscando reestructuración a escala regional; pero se conserva comercio balanceado ArgentinaBrasil, generando redes corporativas con incierta salida global. Elementos del régimen automotriz: (a) Canjes de contingentes de autos-partes libres de aranceles en proporción negociada. Hasta marzo 2015, Argentina - por cada dólar que exporte a Brasil - puede importar \$1,5. Este valor se redujo desde \$1,95 en julio 2013 (Cepal 2014). (b) Contenido regional frente a terceros. (c) Contenido local frente a otros socios.

59 Sobre una mercancía que, tras ingresar a un miembro del Mercosur pagando AEC pasa al territorio de otro.

60 Cuando Brasil devaluó el real en 1999, Argentina (bajo convertibilidad) no pudo responder adecuadamente, y su balanza comercial se deterioró de manera grave.

61 La abrumadora mayoría de los bonistas extranjeros afectados terminaron por aceptar grandes recortes del valor nominal en dos renegociaciones, en 2005 y en 2010. Pero una minoría de recalcitrantes (exigiendo pago completo con intereses) obtuvo fallo favorable de en un juez neoyorquino. El fallo condicionó la continuación de pagos sobre los bonos reestructurados a un arreglo del Estado argentino con los "fondos buitre" demandantes. Argentina entró en default técnico en 2014, afrontando otra crisis financiera.

62 Más difícil aún con su crecimiento desacelerado, estancado en años recientes. 
Así, la dimensión social del Mercosur de los 2000 atrajo a los suramericanos populistas-socialistas. El liberal Uruguay que, junto a los miembros de la ALP, está a la vanguardia latinoamericana en los rankings de clima inversionista, apertura económica y competitividad ${ }^{63}$, quiere acceder a la ALP sin salir del Mercosur. La UA se ha convertido en una camisa de fuerza para el mismo Brasil.

\section{Recurso al CIADI}

La ALP permitió el recurso al CIADI en controversias de inversionista y Estado. El Mercosur no tiene tal norma común. Uruguay se distingue en el Mercosur por su consistente política liberal para atraer inversión directa, que le acerca a la ALP.

$A L P$

El Protocolo Adicional (2014) brinda a los inversionistas socios de la ALP la posibilidad de recurrir al CIADI (entre otras instancias de arbitraje internacional) en sus controversias con un Estado miembro.

Curiosamente, México no se ha adherido al CIADI, aunque, tanto el TLCAN como muchos de sus TLC y TPRI $^{64}$ bilaterales lo contemplen como una de las opciones.

\section{Mercosur}

Brasil (el más soberanista de todos) no ratificó ninguno de los (catorce) TPRI, que había firmado en los noventa, ni se adhirió a la Convención del CIADI (Boeglin, 2013).

Venezuela (2012), Bolivia (2007) y Ecuador (2010) rescindieron la Convención, aunque han conservado varios TPRI (Boeglin, 2013).

Argentina firmó unos 50 TPRI bajo Menem (neoliberal) en los noventa (Valdomir, Carrau, 2013). Los Kirchner (nacionalistas) ignoraban los laudos de compensación, y ponderaban la retirada del CIADI. Sin embargo, en 2013, el gobierno de Cristina Fernández Kirchner acordó compensaciones a cinco empresas extranjeras en una maniobra táctica ante mayores batallas con fondos buitre, norteamericanos.

Paraguay firmó dos docenas de TPRI (la mayoría en los noventa).

63 Informe de clima de negocios (Doing Business) Banco Mundial, Índice de libertad económica (Heritage Foundation), Informe de competitividad global (World Economic Forum) (Blanco, 2014).

64 Tratados de protección recíproca de inversiones. 
Uruguay, a diferencia de sus socios, siguió firmando TPRI en los $2000^{65}$, continúa en el CIADI ${ }^{66}$, y aplica hasta hoy una activa política para atraer inversión.

\section{Dimensión social}

El tándem Lula-Kirchner dotó el Mercosur de una dimensión social (subregional), atractiva para Venezuela, Bolivia, Ecuador. La ALP tiene una limitada función social: crear más empleo, desarrollando políticas públicas que permitan a las pymes aprovechar los flujos de comercio intrazona (Rosales 2013).

\section{Mercosur}

Desde 2003, presidentes de izquierda revisaron el modelo de integración del bloque, profundizando sus dimensiones social $^{67}$ y productiva $^{68}$ sin abandonar completamente el enfoque de mercado de los 90 (Briceño 2014). Así, el Mercosur:

Creó el Fondo de Convergencia Estructural (2006), llamado a reducir las asimetrías intra-bloque (mayores que las existentes entre los socios-ALP). Sin embargo, los beneficiarios Paraguay-Uruguay juzgaron el Fondo para la Convergencia Estructural del Mercosur (FOCEM) insuficiente ${ }^{69}$.

Profundizó la integración social mediante el Consejo de Ministros de Desarrollo Social (2005), el Instituto Social del Mercosur (2007) y el Plan Estratégico de Acción Social (2011) para reducir pobreza, redistribuir riqueza, promover justicia social, regular instituciones de mercado (Briceño, 2014).

Revivió la idea estructuralista de industrialización mediante el Programa Regional de Integración de Producción (2008) (Briceño, 2014).

\section{$A L P$}

Acordó un Fondo de Cooperación ${ }^{70}$ para financiar, en parte, proyectos de pymes y desarrollo social (2013). Firmó un mecanismo de cooperación con la Organización para Cooperación y Desarrollo Económico (OCDE), dirigido al desarrollo de las pymes en integración-competitividad (2014). El Protocolo Adicional (2014) permite a las pymes participar conjuntamente en compras públicas de bienes en toda la región.

65 Una docena de sus casi treinta.

66 Pese a una demanda de la tabacalera multinacional Philip Morris contra su política de salud pública (2010).

67 Política social (distribución, regulación, derechos) reforzada a escala regional (Briceño, 2013).

68 Iniciativas de integración regional para articular políticas comunes de desarrollo económico: resultado de la acción voluntaria de Estados y actores productivos (no solo de fuerzas del mercado) (Briceño, 2013).

69 El FOCEM arrancó con $\$ 100$ millones anuales. Más de dos tercios de las donaciones provenían de Brasil, el resto principalmente de Argentina. Casi la mitad de los fondos beneficiaba a Paraguay y un tercio a Uruguay.

Con aportaciones equitativas de los miembros. 


\section{Unión aduanera}

El Mercosur sigue comprometido con la UA como meta, en parte, por razones geopolíticas. Sin embargo, su construcción (como integración con soberanía mancomunada) ha fallado. Como consecuencia, las negociaciones en bloque encallaron, y la UA se redujo a la prohibición de firmar acuerdos comerciales con terceros individualmente.

La ALP verá la UA como una institución impracticable que conviene evitar. Los miembros-ALP pueden mantener sus antiguos TLC con terceros y son libres para firmar nuevos. Tal autonomía atrae a Uruguay y Paraguay, que pidieron al Mercosur flexibilidad (de la UA) para adherirse también a la ALP.

\section{Mercosur}

Enterrada el ALCA, se relajaron los esfuerzos brasileños para formar el Área de Libre Comercio de Suramérica (ALCSA) y alcanzar el TLC Mercosur y UE. Con socios extra-regionales, el bloque solo ha firmado tres pequeños acuerdos comerciales $^{71}$. El TLC con la UE sigue improbable, tras 15 años de negociaciones ${ }^{72}$.

Brasil evitó los costos de profundización del Mercosur (ceder soberanía en instituciones comunes, extender el FOCEM, respaldar la solvencia de sus socios). Así, el bloque no ha podido ofrecer, en negociaciones de reciprocidad, los atractivos de un homogéneo mercado subregional ${ }^{73}$.

Brasil utiliza la UA y al Mercosur para el crucial propósito político de manejar sus relaciones con Argentina (la única potencia en Suramérica capaz de obstaculizar seriamente su proyección global). Argentina también la usa para atar a Brasil a la región, prevenir que negocie por separado (Malamud, 2013) ${ }^{74}$.

Mientras Brasil ponía todas sus fichas en la Ronda de Doha de la Organización Mundial de Comercio (OMC), prescindir de los acuerdos individuales (bilaterales) parecía una estrategia plausible. Con el fracaso de Doha se ha convertido en una camisa de fuerza (Sorj, 2014).

Sectores empresariales brasileños están preocupados por la multiplicación de TLC bilaterales de otros latinoamericanos con EE. UU. y China, así como por los efectos de la Asociación Transatlántica de Comercio e Inversión (ATCI) ${ }^{75}$. Brasil,

71 Con Egipto, Israel y Palestina.

72 Ciertamente, ningún (otro) socio comercial ha conseguido convencer la UE a desmontar sustancialmente su proteccionismo agrícola. Falta ver, qué logra EE. UU. en la negociación transatlántica. La UE (en su conjunto) aún es el primer socio de Brasil (con una participación del 20.5\% en su comercio total de bienes en 2013), pero China (segunda con 17.2\%) podrá reemplazarla en pocos años (Gratius, Segre, 2014).

73 Brasil tampoco ha absorbido importaciones no competitivas desde sus socios suramericanos. Su inversión directa siguió orientada a los recursos y al mercado, sin formar cadenas integradas de producción (Burges, 2005).

74 Para Brasil, el bloque dejó de tener importancia económica, aunque no para Argentina.

75 Asociación Transatlántica de Comercio e Inversión (macro-TLC EE. UU.-UE). Brasil (con su economía cerrada) solo sufriría bajas mermas de ingresos por desviación de comercio-ATCI. 
al optar exclusivamente por un Mercosur estancado, perdería oportunidades de crecimiento, innovación y conexión a las cadenas globales de valor (Tvevad, 2014).

$A L P$

Ignora la UA si bien se propone avanzar hacia el libre movimiento de los factores, es decir, hacia un mercado común no declarado. En Balassa (1964) la UA es un grado intermedio de integración económica entre la ZLC y el mercado común. Los socios a la ALP tampoco proyectan una unión económica, que implicaría armonizar sus políticas (Ronsain, 2013).

\section{Balanceo institucional a través de la Alianza del Pacífico}

Se evalúa la relación de cada socio de ALP con Brasil, Estado objetivo de ambos balanceos ${ }^{76}$.

\section{México}

Peña Nieto manifestó su deseo de medir el poder de México con el de Brasil, pero enfatizaba la naturaleza comercial de la ALP. La rivalidad mexicano-brasileña se expresó (más allá de la región, pero siempre en plano comercial) en la batalla por la dirección de la $\mathrm{OMC}^{77}$. México sería el líder natural de la ALP, pero no ha asumido tal liderazgo ${ }^{78}$. Su interés en el esquema es comercial, conforme a la prioridad de su política exterior (Morales, Almonte, 2012).

El comercio bilateral (de relevancia intra-industrial) ${ }^{79}$ solo parcialmente está amparado en acuerdos preferenciales ${ }^{80}$, pero los intentos de mayor apertura encallaron en la resistencia de lobbies y la mentalidad de suma cero de los políticos en ambos $\operatorname{lados}^{81}$. El último intento fracasó en $2010^{82}$, pese a las potenciales ventajas de la cooperación $^{83}$.

76 Interinstitucional (contrapeso blando al Mercosur) e intra-institucional (cooperación/balanceo duro/blando en la UNASUR).

77 Derrota del candidato (liberal) mexicano (Ronsain, 2013)

78 El liderazgo de la ALP es difuso (Briceño, 2014).

79 La Cepal (2014) estimó que en 2013, un 34\% del comercio mexicano-brasileño se produjo en sectores con alto potencial intra-industrial; la proporción de productos intermedios alcanzó el $72 \%$.

80 Dos ACE que cubren el 17\% del intercambio de bienes México-Brasil y el ACE automotriz México-Mercosur con acuerdos separados con Brasil, Argentina, Uruguay y firmados en 2002. Estos ACE complementan la Preferencia Regional que México y Brasil se otorgan mutuamente como miembros de ALADI (Cepal, 2014).

81 Temerosos de que la otra nación se beneficiara desproporcionadamente, inclinando la balanza de primacía regional a su favor (Goforth, 2011).

82 Cuando se acordaron términos de referencia de un Acuerdo Estratégico de Integración Económica (Cepal, 2014)

83 Según Maihold (2014), las empresas mexicanas y brasileñas no compiten directamente por mercados ni inversiones; Brasil es hoy el principal destino de la inversión mexicana en el exterior. 
En 2012, México (que tornó su déficit automotriz con el Mercosur en superávit después de 2008) aceptó limitar temporalmente sus exportaciones a Brasil ${ }^{84}$. Según Goforth (2011), México que necesita diversificar sus relaciones centradas en EE. UU., -hará otro intento de libre comercio con Brasil. Así, la ALP podría ser una estrategia mexicana para abrir más el mercado brasileño a mediano plazo, quizás en el marco de un acuerdo ALP-Mercosur.

\section{Colombia}

El gobierno Santos, mientras participaba activamente en la integración con ALP, llegó a cooperar con Brasil en la Unasur. Sin embargo, los lazos colombianos con potencias externas, sobre todo EE. UU., ponían límites a esta cooperación regional.

Colombia era sensible a la incorporación de Venezuela al Mercosur, promovida por Brasil y Argentina. En 2012 se barajaba que la ALP, que reintegró a México al espacio suramericano, podría ser utilizada para balancear blandamente el predominio de Brasil (Nolte, Wehner, 2013).

Colombia (la más conectada a México en la ALP) siguió dando la espalda a Brasil, temiendo la competencia de sus empresas. El comercio bilateral tiene potencial intraindustrial ${ }^{85}$. Ante Brasil y Mercosur, Colombia abre su mercado más lentamente que ante sus socios de la ALP, EE. UU. y la UE.

El gobierno Uribe era reticente a entrar en el Consejo de Defensa Suramericano (CDS) de la Unasur ${ }^{86}$, exigiendo calificar las FARC como organización terrorista ${ }^{87}$ (Dabène, 2014). En 2009, ya como miembro Unasur/CDS, firmó un acuerdo sobre uso extendido de bases colombianas por tropas de EE. UU., para fortalecer una alianza militar que -si bien no se dirigía contra Brasil- ${ }^{88}$ iba a socavar sus intereses geopolíticos en un "balanceo duro colateral" (Flemes, Wehner, 2012) ${ }^{89}$.

Santos, desde su investidura en 2010, demostró mayor compromiso con la

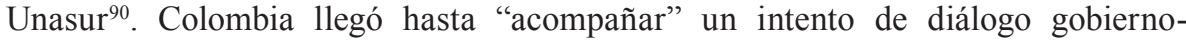

84 El ACE automotriz se renegoció: el monto anual que México puede exportar a Brasil, libre de aranceles en el sector, se fijó en $\$ 1450$ millones en 2012. Dicho monto se elevó a \$1560 millones en 2013 y a \$1640 millones en 2014. En 2015 volvería el libre comercio sectorial sin límites (Cepal, 2014). Argentina suspendió por tres años la importación de autos-partes mexicanos sin arancel.

85 Complementariedad-competencia en industria farmacéutica, química ampliada (Cepal, 2014).

86 La firma del Tratado Constitutivo de la Unasur (2008) fue precipitada por el bombardeo colombiano de un campamento guerrillero de las FARC en territorio ecuatoriano y la reactivación de la IV Flota de la Marina estadounidense. La crisis regional desatada por la incursión colombiana empujó a Lula a acelerar la fundación de la Unasur y de su CDS (Dabène, 2014).

87 Que habría legitimado la violación colombiana de la soberanía de Ecuador.

88 Bajo el Plan Colombia, las FARC eran combatidas por el Ejército colombiano - en estrecha cooperación con fuerzas armadas y de inteligencia de EE. UU, en parte por fuera de las fronteras colombianas.

89 Finalmente, el acuerdo fue declarado inexequible por la Corte Constitucional colombiana.

90 Chávez y Kirchner en investidura de Santos, normalización con Venezuela, Secretaría General compartida. 
oposición en Venezuela en una troika de vecinos ${ }^{91}$. El desempeño de Samper como secretario general reforzaría aún más el compromiso colombiano con la Unasur.

Sin embargo, bajo el gobierno de Santos también había comportamientos colombianos, catalogables como balanceadores. En 2013 se firmó un acuerdo con la OTAN sobre protección de información confidencial, que reveló interés (mutuo) por participación colombiana en futuras misiones ${ }^{92}$. Según Prieto (2013), Colombia volvió a "echar palo en la rueda" de la naciente Comunidad Suramericana de Seguridad"3.

Otro ejemplo era el propósito, atribuido a Colombia y Chile (Piñera), de utilizar la ALP para balancear blandamente la influencia regional de Brasil (Nolte, Wehner, 2013). Esto habría requerido coordinación política en la ALP (entre sus miembros suramericanos y México). Sin embargo, los cancilleres de Chile (Bachelet) y Colombia recalcaron que la ALP no tenía tal mecanismo (Muñoz, 2014a; SELA, 2014).

\section{Chile}

Bachelet realizó un espectacular reacercamiento a Brasil, e insistió en una convergencia ALP y Mercosur. Criticó la "ideologización" de la política exterior chilena bajo su predecesor ${ }^{94}$. Se acercó a su homóloga brasileña Rousseff y su vecina argentina Cristina Fernández Kirchner, con quienes comparte el compromiso de mayor equidad distributiva.

Según el canciller Muñoz (2014), la ALP y el Mercosur "pueden ser ladrillos para la construcción de un proyecto mayor y más incluyente de integración latinoamericana".

Las cifras comerciales explican la posición de Bachelet. Brasil recibe más exportaciones chilenas que la ALP. Las importaciones chilenas desde Brasil y Argentina (sumadas) son casi un 50\% superior a las provenientes de Colombia, México y Perú. Brasil y Argentina son el primer y segundo destino de la inversión chilena en el exterior (Francke, 2014).

Además, un excesivo compromiso de la ALP tampoco concordaría con la estrategia comercial de Chile que -con sus múltiples TLC - no solo ha buscado acceder a todos los mercados relevantes, sino minimizar su dependencia de uno solo (Wehner, 2011).

91 Las negociaciones con las FARC arrancaron en 2012 con facilitación internacional ad hoc (por fuera de toda estructura establecida) pero apuntaban hacia un proceso de paz con benignos efectos para el vecindario.

92 Instructores colombianos entrenan (en tácticas de contrainsurgencia y antidroga) a miles de militares y policías de las Américas y del mundo, en una tercerización de este servicio profesional por las agencias de defensa de EE. UU. (Richani, 2013).

93 En 2014, Colombia firmó con la UE un acuerdo marco para participar en misiones comunitarias de seguridad y defensa (empleos y posconflicto para militares colombianos).

94 Implicando que Piñera habría privilegiado los miembros de la ALP sobre los miembros de Mercosur. 
Perú

Perú es la menor economía de la ALP y Humala ha tenido un perfil bajo. Si bien conformar la ALP era una iniciativa peruana, incorporar a México no la era. Desde 2003, Lima viene cultivando con Brasilia una alianza estratégica, profundizada por Alan García y continuada por Humala, cuya campaña presidencial recibió apoyo del Partido de los Trabajadores de Lula-Rousseff (Novak, Namihas, 2012) ${ }^{95}$.

\section{¿Cómo hacer amigable la ALP para su región?}

\section{Competencia y cooperación}

Los suramericanos de la ALP cooperan con Brasil en la Unasur bilateralmente, mientras procuran consolidar su integración económica. México también limita su rivalidad con Brasil -y su interés en la ALP-al ámbito comercial. Todos abandonaron cualquier retórica anti Mercosur.

Sin embargo, la ALP, para tener cohesión, debería ir cambiando la situación en que sus dos miembros clave están más integrados al Mercosur que a ella misma. Elevar su escaso comercio intrarregional e intra-industrial a un nivel comparable con el Mercosur.

La consolidación de la ALP tomará años, y su éxito no está asegurado. Por tanto, le conviene mostrar una cara amigable al resto de su región.

\section{¿Qué podría hacer la ALP para ser amigable?}

No moldear servilmente el TLCAN, la ATP.

Rosales (2013). Ver subtítulo de la ALP entre regionalismo/panamericanismo (primer matiz).

Mostrarse dispuesta para admitir antiguos miembros del ARCO.

Tras Costa Rica, Panamá podría admitir a centroamericanos más rezagados con trato especial; no solo a Guatemala y Honduras (ya observadores), sino también a Nicaragua, auspiciando su reconciliación (y TLC) con Colombia, por muy difícil que parezca $^{96}$. Incorporar a Ecuador tiene importancia geopolítica (pese a las diferencias ideológicas y la dificultad de integrar su economía dolarizada).

95 Interés peruano y brasileño: interconexión bioceánica a través del territorio del otro.

96 Colombia no retiró sus buques de las aguas adjudicadas a Nicaragua por la Corte Internacional de Justicia en 2012. El Gobierno Ortega decidió adelantar el proyecto de un canal interoceánico con una empresa china y solicitar ayuda militar rusa para su seguridad marítima. 


\section{Conversar con el Mercosur de cooperación}

La ALP debe hacerlo (incluso en el enfoque realista del balanceo interinstitucional), pues aún tiene menos cohesión comercial y productiva que el Mercosur, y necesita una póliza de seguro para el caso, si su integración no avanza adecuadamente.

La Cepal (2014) propuso a los dos esquemas una agenda conjunta de trabajo, que omite la desgravación arancelaria (pues el Protocolo Adicional ni siquiera ha entrado en vigor), pero contiene varias áreas en las que una cooperación más amplia tendría sentido, aunque la ALP quería avanzar sola y rápidamente.

Propuesta Cepal (2014): a. Facilitación de comercio ${ }^{97}$. b. Acumulación de origen ${ }^{98}$. c. Movilidad de personas. d. Estadísticas comparables sobre comercio de servicios. e. Ciencia, tecnología, innovación prospectiva ${ }^{99}$. f. Aprovechamiento sostenible de recursos naturales. g. Infraestructura de transporte y tránsito (Atlántico y Pacífico) ${ }^{100}$. h. Energía ${ }^{101}$. i. Política industrial (fomento productivo) ${ }^{102}$. j. Aproximación conjunta a Asia y Pacífico ${ }^{103}$. k. Coordinación en temas del G-20 $0^{104}$. 1. Turismo ${ }^{105}$.

\section{Mercosur UA-ZLC: costos para Brasil}

Indirectamente, la consolidación de la ALP depende también de la conclusión de la ATP y de su aprobación por el Congreso estadounidense. El arranque de la ATP impulsaría a la UE a concluir su ATCI con EE. UU. ${ }^{106}$.

Si la ALP no se consolida, un macro de ACE en la Unasur (sin México) será posible. Si la ALP se consolida, la ATP se ratifica y la ATCI progresa, aumentará la presión sobre Brasil para concluir nuevos acuerdos comerciales, con o sin los socios de Mercosur.

Brasil siempre ha sido renuente a profundizar la UA y Mercosur. Sin embargo, su reversión a una ZLC (o flexibilidad equivalente) demostraría la incapacidad de Brasil para mantener la disciplina colectiva del bloque, y podría desatar una desintegración

97 Interoperabilidad de ventanillas únicas de comercio exterior, gradual armonización/reconocimiento mutuo de normas técnicas, sanitarias, fitosanitarias, adopción de certificados digitales de origen.

98 Existe entre los miembros del Mercosur y de la ALP (cuando el Protocolo Adicional entre en vigor), mecanismos limitados en los ACE de la CAN y Mercosur. Propuesta: avanzar hacia un conjunto único de reglas de origen y un mecanismo de acumulación.

99 Red de educación científica, posgrados, pasantías a escala regional; colaboración I+D con sector privado; red multinivel de prospectiva.

100 Compatibilizando marcos normativos.

101 Interconexión eléctrica, intercambios de gas natural.

102 Coordinar apoyo a las cadenas (consideradas) prioritarias, la internacionalización de pymes.

103 Consensuarían posiciones relativas a vínculos con China, facilitando acuerdos en Celac.

104 Incluir temas de gobernanza mundial en agenda ALP-Mercosur, aprovechando que Argentina, Brasil y México pertenecen al Grupo de los 20 .

105 Circuitos turísticos plurinacionales.

106 Para evitar desviación de comercio e inversiones. 
tipo CAN. Sería un cambio desfavorable para Brasil en la arquitectura institucional regional, por lo menos, en el enfoque realista del balanceo interinstitucional ${ }^{107}$.

Si Brasil firmara (individualmente) TLC bilaterales con las potencias comerciales, sus actuales socios (suramericanos) verían erosionar las preferencias conseguidas anteriormente de él y de sus nuevos socios. El Mercosur se disgregaría y el liderazgo regional de Brasil sufriría. Argentina también buscaría acuerdos separados, desamarrándose de Brasil políticamente, y obstaculizando sus proyectos globales.

\section{Un macro de ACE ALP y Mercosur}

Aplazaría el problema UA de Brasil, pues los socios de Mercosur podrían negociar como bloque (su acceso preferencial al mercado de México/ALP).

El acceso mejorado al mercado de Mercosur, incluyendo a Venezuela, compensaría los suramericanos de la ALP (competitivos) por la erosión de sus preferencias recibidas de México. (Colombia podría recuperar algo de su comercio intra-industrial con Venezuela, significativo en los noventa) ${ }^{108}$.

El comercio ampliado eliminaría barreras ante las incipientes cadenas latinoamericanas de valor, beneficiando toda la región (Kotschwar, 2014).

La integración con la ALP estimularía los socios de Mercosur a abandonar sus políticas más distorsionadas (Kotschwar, 2014).

Si bien los líderes de la ALP resistieran para que la política regional retrasara su esquema y ablandara sus objetivos, una real convergencia requeriría a la ALP adoptar algunas sugerencias para hacerse amigable.

\section{Visión cepalina}

En la visión idealista de la Cepal (2014), la ALP y el Mercosur (con su agenda conjunta) catalizarían la conformación de una macro-región Latinoamérica, basada en la convergencia entre todos los esquemas subregionales ${ }^{109}$.

107 En un enfoque liberal, tal reversión brindaría una oportunidad para la cooperación ALP-Mercosur, pues se compartirían miembros que servirían como puentes (Nolte, 2014). Incluso el actual estatus de observador de Uruguay y Paraguay en la ALP puede ser visto -más que un elemento de división en el Mercosur- como un elemento de puente entre los dos esquemas (Tvevad, 2014).

108 Venezuela (tras su retiro de la CAN/G3) redujo sus importaciones de carros colombianos (sustituyéndolas con compras argentinas). Los autopartes de México y Chile ingresan a Colombia sin arancel desde 2011, mientras la desgravación con el Mercosur solo finalizará en 2017 (Gayá, Michalczewsky, 2014). En un lustro, México triplicó sus ventas de carros a sus (actuales) socios de la ALP y se convirtió en el primer proveedor de Colombia. En Colombia, solo Renault-Sofasa produce para exportar a México. Colombia tiene un déficit de $\$ 4000$ millones en su comercio con México.

109 Tal macro-región, donde los elementos de cooperación prevalecerían sobre los de competencia, y las diferencias serían manejables, permitiría evitar una división artificial Atlántico-Pacífico. 


\section{Conclusiones}

La competencia ALP y Mercosur es de baja intensidad. México y Chile están más ligados comercialmente a Brasil-Mercosur que a sus socios de la ALP. Si el Protocolo Adicional (2014) se realiza, generando cadenas de valor intrazona, la ALP podrá competir más intensamente con el Mercosur.

Entre los miembros/asociados-Mercosur, la ALP (si su historia es guía) solo competiría por Uruguay, y se interesaría también en Venezuela y Ecuador, siempre que cambiaran de régimen político-económico (mejorando su relación con EE. UU.).

El cambio chileno mermó la utilidad de la ALP para balancear al Mercosur. A diferencia de México, Chile (Bachelet) se acercó políticamente a Brasil, con el cual comparte el compromiso de mayor equidad distributiva. Si bien se comprometió a no diluir la ALP, promueve su convergencia con el Mercosur.

La ALP hace bien en conversar con el Mercosur, pues tiene menos cohesión comercial-productiva, y necesita una póliza de seguro para el caso, si su integración no avanza adecuadamente.

Si la ALP se consolida y las negociaciones mega-regionales concluyen, aumentará la presión sobre Brasil para concertar nuevos acuerdos comerciales, con o sin sus socios de Mercosur.

Si Brasil es reacio a profundizar la UA-Mercosur, su reversión a ZLC amenazaría al bloque con disgregación comercial. La solución menos incómoda para Brasil sería un macro-ACE (intra-ALADI), que el Mercosur negociaría en bloque con la ALP.

México (que necesita diversificar desde EE. UU.) haría otro intento de libre comercio con Brasil, en la forma de un acuerdo ALP-Mercosur, confiando en su más eficiente planta manufacturera.

El acceso mejorado al mercado Mercosur (incluyendo a Venezuela) compensaría los suramericanos de la ALP por la erosión de sus preferencias recibidas de México. El comercio ampliado eliminaría barreras ante las incipientes cadenas latinoamericanas de valor. La integración tornaría a la ALP más cooperativa (amigable) y al Mercosur más competitivo.

\section{Referencias}

Alianza del Pacífico (2011). Declaración Presidencial sobre la Alianza del Pacífico. Cumbre de Lima para la Integración Profunda, 28 abril. Recuperado de http:// alianzapacifico.net/documents/AP_Declaracion_Lima_I_Cumbre.pdf

Alianza del Pacífico (2012). Acuerdo Marco de la Alianza del Pacífico. Documentos de la VIII Cumbre, 11 de febrero de 2014. Recuperado de http://alianzapacifico. net/documents/2014/Acuerdo_Comercial.pdf 
Alianza del Pacífico (2012). Exposición de motivos del Proyecto de Ley por medio del cual se aprueba el Acuerdo Marco de la Alianza del Pacífico. www.tlc.gov. co/descargar.php?id=66920, http://wsp.presidencia.gov.co/Normativa/Leyes/ Documents/LEY\%201721\%20DEL\%2027\%20DE\%20JUNIO\%20DE\%202014. pdf

Alianza del Pacífico (2014). Protocolo Adicional al Acuerdo Marco de la Alianza del Pacífico. Documentos de la VIII Cumbre, 11 febrero. Recuperado de http:// alianzapacifico.net/documents/2014/PROTOCOLO_COMPLETO.pdf

ALADI (marzo, 2012). Evolución del comercio intraindustrial en la ALADI, ALADI/ SEC. Estudio 201. Montevideo.

Balassa, B. (1964). Teoría de la integración económica. México: UTEHA.

Bechle, K. (2011). Kein Auslaufmodell: 20 Jahre Mercosur. GIGA Focus Lateinamerika, núm. 3. ISSN 1862-3573.

Betancourt, R. (2012). Colombia frente a los espacios regionales de cooperación e integración. En Jost, S. (ed.). Colombia: ¿una potencia en desarrollo? Escenarios $y$ desafios para su política exterior. KAS.

Blanco, A. (2014). La Alianza del Pacífico: Un largo camino por recorrer hacia la integración. Recuperado de http://www.wilsoncenter.org/sites/default/files/ La_Alianza_del_Pacifico_Blanco_0.pdf

Bloomberg. (2014). Panel de la Alianza del Pacífico. Nueva York, septiembre 22. Bloomberg Latin America Forum.

Boeglin, N. (diciembre, 2013). El CIADI y América Latina: Críticas, denuncias y busca de alternativas. The Bretton Woods Project.

Brenner, Ph., Hershberg, E. (2014). Washington's Asia-Pacific Response to a Changing Hemispheric Order. En Hershberg, E., Serbin, A., Vigevani, T. (eds.). El hemisferio en transformación: Regionalismo, multilateralismo y políticas exteriores en un entorno cambiante. Pensamiento Propio, CRIES, (39).

Briceño, J. (2013). Ejes y modelos en la etapa actual de la integración económica regional en América Latina. Estudios Internacionales, 45 (175). Universidad de Chile.

Briceño, J. (2014). Regional dynamics and external influences in the discussions about the model of economic integration in Latin America (February). Robert Schuman Centre for Advanced Studies Research. Paper No. 2014/11. SSRN: http://ssrn. com/abstract $=2393346$

Burges, S. (2005). Bounded by the Reality of Trade: Practical Limits to a South American Region. Cambridge Review of International Affairs, 18(3). 
Cepal. (2014). La Alianza del Pacífico y el Mercosur. Hacia la convergencia en la diversidad. Santiago. Recuparado de http://repositorio.cepal.org/bitstream/ handle/11362/37304/S1420838_es.pdf?sequence=1

Dabène, O. (2014). La cuarta ola de regionalismo. En Quenan, C., Velut, S. (dir.). Los desafios del desarrollo en América Latina. (pp. 64-95). Institut des Amériques.

Echebarría, L., Estevadeordal, A. (marzo, 2014). Alianza del Pacífico: un nuevo motor de integración regional. En Foxley, A., Meller, P. (eds.). Alianza del Pacífico: En el proceso de integración latinoamericana. Cieplan-BID. Santiago.

Falomir, N. (2014). L'élargissement du Mercosur: accès accidentel du Venezuela et autres processus d'adhésion en cours. Chroniques du Centre d'Études Interaméricaines (Université Laval).

Flemes, D., Wehner, L. (2012). Strategien südamerikanischer Sekundärmächte. GIGA Focus Lateinamerika, núm. 4.

Foxley, A. (2014). Nuevo desafío para América Latina: Integración productiva. En Foxley, A., Meller, P. (eds.). Alianza del Pacífico: En el proceso de integración latinoamericana. Cieplan-BID. Santiago.

Francke, M. (2014). Alianza del Pacífico: Perspectiva de Chile. En Foxley, A., Meller, P. (eds.). Alianza del Pacífico: En el proceso de integración latinoamericana. Cieplan-BID. Santiago.

Gayá, R., Michalczewsky, K. (mayo, 2014). El comercio intrarregional sudamericano: patrón exportador y flujos intraindustriales. Nota Técnica núm. IDB-TN-583. BID-INTAL.

Goforth, S. (2011). Mexico-Brazil Economic Integration. In Latin America: A Region Takes Shape. World Politics Review. Special Report.

Gratius, S., Segre, M. (2014). Brazil: what to expect from the new 'old' government? FRIDE Commentary, núm. 20.

He, K. (2007). Institutionalizing Security: Institutional Realism and Multilateral Institutions in Southeast Asia. (Ph. D. Dissertation). Arizona State University.

Hershberg, E. (2014). Trans-Pacific Partnership: A Framework for U.S.-Latin America Relations? AULA-Blog. Washington: American University.

Kotschwar, B. (2014). The Pacific Alliance and Mercosur: Narrowing the Gap? Real Time Economic Issues Watch. Peterson Institute for International Economics. Washington.

Lee, S. (2012). The Evolutionary Dynamics of Institutional Balancing in East Asia. East Asia Institute. Recuperado de http://www.eai.or.kr/data/bbs/eng _ report/20120209104282.pdf 
Mace, G., Bélanger, L. (1999). The Americas in Transition: The Contours of Regionalism. Lynne Rienner Publishers. Boulder.

Mace, G., Thèrien, J. (2007). Inter-American Governance: A Sisyphean Endeavor? En Mace, G., Thèrien J., Haslam, P. (Eds.). Governing the Americas: Assessing Multilateral Institutions. Lynne Rienner Publishers, (Cap 14, pp. 35-50). Boulder. ISBN 978-1-58826-533-3.

Maihold, G. (2014). Brasilien - Mexiko 0:0, Warum die beiden nicht miteinander können - aber schon gar nicht gegen einander. IPG-Journal.

Malamud, A. (2013). Overlapping Regionalism, Not Integration: Conceptual Issues and the Latin American Experiences. EUI, RSCAS 2013/20.

Mander, B. (2014). Mercosur views Pacific Alliance with unease. Financial Times.

Morales, M., Almonte, L. (2012). ¿Un nuevo intento a la integración latinoamericana?, México y la Alianza del Pacífico. Cuadernos sobre Relaciones Internacionales, Regionalismo y Desarrollo, 7(14).

Muñoz, H. (2014). Convergencia en la diversidad: la nueva política latinoamericana de Chile. El País, 13 de marzo. Recuperado de http://elpais.com/elpais/2014/03/12/ opinion/1394642773_153377.html

Muñoz, H. (2014a). Chile's New Foreign Policy. Wilson Center, Washington. Recuperado de https://www.youtube.com/watch?feature=player_embedded\&v= mjiABhnK5hw

Nolte, D. (2014). Latin America's New Regional Architecture: a cooperative or segmented regional governance complex? GIGA.

Nolte, D., Wehner, L. (2013). The Pacific Alliance Casts Its Cloud over Latin America. GIGA Focus, International Edition, núm. 8.

None, J. (2014). La Alianza del Pacífico: tres años después. Web-FAL. Recuperado de http://www.revistafal.com/index.php?option $=$ com_content\&view $=$ article \&id $=17$ 66:alianza-del-pacifico-none-tres-anos-despues \& catid $=156 \&$ Itemid $=490$

Novak, F., Namihas, S. (2012). Las relaciones entre el Perú y Brasil (1826 - 2012). Serie: Politica Exterior Peruana. KAS. ISBN 978-9972-671-13-5.

O’Keefe, T. (2014). Prospects for Energy Integration in Latin America, AULA Blog. American University, Washington.

Quenan, C. (2014). América Latina y la crisis económica internacional. En Quenan, C., Velut, S. (dir.). Los desafios del desarrollo en América Latina. (2a. ed., pp. 25-63). Institut des Amériques.

Ramírez, J. (2012). Conferencia del Ministro Plenipotenciario de la Misión de Colombia ante la OEA. Universidad Autónoma de Bucaramanga, 14 de agosto. 
Ronsain, O. (noviembre, 2013). L'Alliance du Pacifique: Etat des lieux, enjeux et perspectives. Sciences Po, OPALC. París.

Rosales, O. (2013). Osvaldo Rosales de Cepal analiza Alianza del Pacífico. Diario Financiero TV Chile. https://www.youtube.com/watch?v=BDaZ00PmvHQ[AG1]

Rubio, M. (2014). US-Colombia partnership should be strengthened. http://www. miamiherald.com/opinion/op-ed/article4001535.html

Sanahuja, J. (2012). Regionalismo post-liberal y multilateralismo en Suramérica: El caso de Unasur. En Serbin, A. et al. (eds.). El regionalismo "post-liberal" en América Latina y el Caribe. Anuario de la Integración Regional de América Latina y el Gran Caribe.

SELA. (2014). Alianza Pacífico y Mercosur buscan complementarse por la integración regional. Servicio Informativo del SELA.

Sorj, B. (2014). Brazil and the Liberal World Order in the 21st Century. En Flockhart et al. Liberal Order in a Post-Western World, (pp. 71-82). Washington: Transatlantic Academy.

Tvevad, J. (2014). The Pacific Alliance: Regional integration or fragmentation? UE, Parlamento Europeo, Dirección General de Políticas Externas. Bruselas.

Valdomir, S., Carrau, N. (2013). El Mercosur y el tratamiento de las inversiones. América Latina en movimiento, núm. 485. Quito: ALAI.

Wehner, L. (2011). Chile's Rush to Free Trade Agreements. Revista de Ciencia Política, $l(2)$.

Weiffen, B., Wehner, L., Nolte, D. (2013). Overlapping regional security institutions in South America: The case of OAS and UNASUR. International Area Studies Review, 1(16), 370-389. 